\title{
Comparison of bypass versus primary angioplasty for lower extremity chronic limb-threatening peripheral arterial diseases
}

\author{
@Mustafa Özer Ulukan, @Atalay Karakaya, @Murat Uğurlucan, @Korhan Erkanlı \\ İstanbul Medipol University, Faculty of Medicine, Department of Cardiovascular Surgery, İstanbul, Turkey
}

Cite this article as: Ulukan MÖ, Karakaya A, Uğurlucan M, Erkanlı K. Comparison of bypass versus primary angioplasty for lower extremity chronic limb-threatening peripheral arterial diseases. J Health Sci Med 2021; 4(3): 383-387.

\begin{abstract}
Aim: Peripheral arterial diseases (PAD) is seen frequently with increasing age, and have a prevalence of about $20 \%$ over 70 years of age. We aimed the results of two different treatment approaches as open surgical procedures and radiological interventions.

Material and Method: We reviewed the data of PAD from the online data system of the hospital. The patients treated by endovascular femoropopliteal revascularization versus open surgical femoropopliteal graft bypass between January 2016 and December 2019 were enrolled in to study. Eighty limbs of 67 patients with the symptomatic severe occlusive disease and results were evaluated in the aspect of reducing ischemia and prevention of amputation in this retrospective study.

Results: 67 patients were divided into two groups. Group $1(n=29)$ was the interventional PTA/S group, group $2(n=38)$ was the open surgical bypass group. 8 of the patients in Group 2 and 5 of patients in Group 1 had bilateral lesions. Patients were at a mean age of $63.44 \pm 8.98$ years. The mean time of hospitalization time was significantly longer following a first-time bypass ( 10 vs. 8 days). The success of results was ending of claudication and ischemia and prevention of amputation of an extremity. In these aspects, there was no difference between procedure types.

Conclusion: In the aspect of the length of hospital stay and infection, interventional procedures seem more benefit however in longterm evaluation, freedom from reintervention or redo bypass was significantly higher in the bypass group ( $92 \%$ vs $79 \% \mathrm{p}<0.01$ ).
\end{abstract}

Keywords: Peripheral arterial diseases, peripheral bypass surgery, angioplasty.

\section{INTRODUCTION}

Peripheral arterial diseases (PAD) are seen frequently with increasing age and have a prevalence of about $20 \%$ over 70 years of age. The etiology of PAD is generally associated with atherosclerosis so it is accepted as a comorbidity of cardiovascular diseases even increases mortality even 5 to 6 -fold (1).

There are currently two types of treatment of chronic limb-threatening ischemia (CLTI) like open surgical bypass, or percutaneous interventions including balloon angioplasty, stent, and atherectomy (2). In the aspect of long-term clinical durability and graft patency, bypass surgery has advantages but operation risk and comorbidity of patients with increasing age also increase the short-term morbidity (3). On the other hand, invasive interventions are being minimally invasive, have lower morbidity and mortality in the short-term, faster procedural times, and a reduced hospital stay (4). In patients with severe occlusive disease of the femoropopliteal segment, the advantages of endovascular versus bypass revascularization remain debated.

In the current study, we present our experiences and results and aimed to compare the advantages and outcomes of both treatment methods.

\section{MATERIAL AND METHOD}

\section{Study Design}

The study was carried out with the permission of NonInterventional Clinical Researches Ethics Committee of İstanbul Medipol University (Date: 03.18.2021, Decision No: 357$)$. This study was carried out in accordance with the principles of the Declaration of Helsinki.

On retrospective analysis of the bypass versus primary angioplasty for lower extremity chronic limb-threatening peripheral arterial diseases was received from our institution of the university. Informed consent for 
patient's information was taken before hospitalization by the patient(s) or a legally authorized representative.

We reviewed the data of PAD from the online data system of the hospital. The patients treated by endovascular femoropopliteal revascularization versus open surgical femoropopliteal graft bypass between January 2016 and December 2019 were enrolled in to study. Eighty limbs of 67 patients with the symptomatic severe occlusive disease and results were evaluated in the aspect of reducing ischemia and prevention of amputation in this retrospective study.

All of the patients were divided into two groups as Group 1 and Group 2, as interventional and open surgical bypass consecutively.

\section{Procedures}

The whole of the endovascular procedures (percutaneous cutaneous angioplasty) was performed under local anesthesia and with/without intravenous sedation. $6 \mathrm{~F}$ Femoral sheaths were inserted with the help of vascular ultrasonography for vascular access and $5000 \mathrm{U}$ intraarterial heparins were given. In patients of proximal of the superficial femoral artery, lesions were accessed contralateral extremity with a crossover technique. And we also used the ipsilateral antegrade approach in cases of mid and distal SFA lesions. For the treatment of femoropopliteal lesions, $0.035^{\prime \prime} 260 \mathrm{~cm}$ hydrophilic guidewires were preferred. $5 \mathrm{Fr}$ x $135 \mathrm{~cm}$ Navicross microocclusion catheters (Terumo) were used in total occluded arteries. In cases of guidewire pass not thorough subintimal section Rotablator System (Boston Scientific Corporation; Scimed, Plymouth, MN, USA) was used and after than drug-coated balloons in diameters of 4-6 $\mathrm{mm}$ were used in the femoropopliteal section of arteries in all patients.

In open surgical bypass graft enrolled patients synthetic 8 $\mathrm{mm}$ PTFE graft with the ring or saphenous vein was used for bypass from common femoral arteries to popliteal arteries under general anesthesia. And patients were heparinized in 24 hours to ensure aPTT level in a range of 50 to 70 . Then they were discharged with acetylsalicylic aside $100 \mathrm{mg} /$ day and clopidogrel $75 \mathrm{mg} /$ day. In bilateral cases, the other side was done one week later.
The data were analyzed with Statistical Package for Social Sciences, SPSS 20. Numeric values are expressed as mean, standard deviation, and percentage. $\mathrm{p}<0.05$ was considered statistically significant.

\section{RESULTS}

Sixty-seven patients were evaluated in two groups. Group $1(\mathrm{n}=29)$ was the interventional PTA/S group, group $2(n=38)$ was the open surgical bypass group. They were undergoing 80 procedures like endovascular femoropopliteal revascularizations (8 of patients have bilateral lesions) and surgical bypass procedures (5 of patients had bilateral lesions). While 14 of procedures were done by saphenous vein, 29 of procedures were done by PTFE graft in group 2. Patients were at a mean age of $63.44 \pm 8.98$ years (Table 1). The mean age of Group 2 (bypass) was smaller (61 vs. 65 years, $P>0.01$ ) and the incidence of the male was higher (65\% vs. $61 \%$; $>0.01$ ). The mean and std of CCI (Charlson Comorbidity Index) of patients were $3.35 \pm 1.72$ and $3.51 \pm 1.49$ in Group 1 and Group 2 consequently, and there wasn't meaningful difference. The Mean follow-up time was 18 months in a range of 14 to 22 months. Revascularization indication was being symptomatic with claudication or ischemia, and radiologically obtained stenosis of more than $\geq 70 \%$ of the SFA. And classified as stage 2-6, regarding Rutherford classification (Table 2). The mean of hospital stay was significantly higher following operation (10 vs. 8 days, $\mathrm{P}<.001)$, and in two groups, ischemia resolved and extremities were freed from amputation. Although perioperative mortality was higher in group 1, due to intracerebral hemorrhage, the rate of complications like surgical site infection and hematoma following a bypass was higher in group 2 (13.15\%).

The mean hospital stay was significantly longer in surgical bypass patients ( 4.38 vs. 1.39 days, $\mathrm{P}<.001)$. Before the procedure, patients' lesions had no significant differences in Rutherford classification (Table 2). However, in the classification of TASC C and D were higher in the bypass group $(\mathrm{p}<0.01)$ (Table 3$)$.

\begin{tabular}{|c|c|c|c|c|}
\hline & Group $1(n=29)$ & Group $2(n=38)$ & Total & P value \\
\hline Age (mean) & $65.9 \pm 8.9$ & $61.6 \pm 8.5$ & $63.4 \pm 8.9$ & $>0.01$ \\
\hline \multirow{2}{*}{$\begin{array}{l}\text { Male } \\
\text { Female }\end{array}$} & $19(65.5 \%)$ & $26(68.4 \%)$ & $45(67.1 \%)$ & $>0,01$ \\
\hline & $10(34.4 \%)$ & $12(31.5 \%)$ & $22(32.8 \%)$ & $>0.01$ \\
\hline Diabetes mellitus & $14(48.2 \%)$ & $20(51.6 \%)$ & $34(50.7 \%)$ & $>0.01$ \\
\hline Hypertension & $14(48.2 \%)$ & $17(44.7 \%)$ & $31(46.2 \%)$ & $>0.01$ \\
\hline Smoking & $13(44.8 \%)$ & $18(47.3 \%)$ & $31(46.2 \%)$ & $>0.01$ \\
\hline Hyperlipidemia & $11(37.9 \%)$ & $15(39.4 \%)$ & $26(38.8 \%)$ & $>0.01$ \\
\hline Hospital stay & $1.39 \pm 0.5$ & $4.38 \pm 0.8$ & $3.1 \pm 1.6$ & $<0.01$ \\
\hline Perioperative mortality & $2(6.88 \%)$ & 0 & $2(2.9 \%)$ & NA \\
\hline Surgical site infection & $1(3.4 \%)$ & $5(13.1 \%)$ & $6(8.9 \%)$ & $<0.01$ \\
\hline Patients presenting with gangrene & $3(10.3 \%)$ & $2(5.2 \%)$ & $5(7.4 \%)$ & NA \\
\hline
\end{tabular}


Table 2. Rutherford classification of PAD

\begin{tabular}{|ccccccc}
\hline Grade & Category & Clinical Description & $\begin{array}{c}\text { Group 1 N=29 } \\
\text { (percent) }\end{array}$ & $\begin{array}{c}\text { Group 2 N=38 } \\
\text { (percent) }\end{array}$ & $\begin{array}{c}\text { P } \\
\text { value }\end{array}$ \\
\hline 0 & 0 & Asymptomatic & 0 & 0 & NA \\
I & 1 & Mild claudication & 0 & NA \\
I & 2 & Moderate claudication & $12(41.3 \%)$ & $16(42.1 \%)$ & $>0.01$ \\
I & 3 & Severe claudication & $7(24.1 \%)$ & $13(34.1 \%)$ & $>0.01$ \\
II & 4 & Ischemic rest pain & $7(24.1 \%)$ & $7(18.4 \%)$ & $>0.01$ \\
III & 5 & Minor tissue loss-nonhealing ulcer, focal gangrene with diffuse pedal ischemia & $1(3.4 \%)$ & $1(2.6 \%)$ & $>0.01$ \\
III & 6 & Major tissue loss-extending above transmetatarsal level, frank gangrene & $2(6.8 \%)$ & $1(2.6 \%)$ & $>0.01$ \\
\hline \multicolumn{7}{r}{} \\
\hline
\end{tabular}

Table 3. TASC (Trans-Atlantic Inter Society Consensus) classification

\begin{tabular}{|ccccc|}
\hline Grade & Clinical Description & Group 1 n (\%) & Group 2 n (\%) & P value \\
\hline Type A & Single stenosis $<10 \mathrm{~cm}$ in length & $8(27.5 \%)$ & $6(15.7 \%)$ & $>0.01$ \\
Type B & Multiple stenosis and occlusion & $16(55.1 \%)$ & $9(23.6 \%)$ & $<0.01$ \\
\hline Type C & Multiple stenosis or occlusions totaling $>15$ cm with heavy calcification & $3(10.3 \%)$ & $13(34.2 \%)$ & $<0.001$ \\
Type D & Chronic total occlusion of SFA $>20 \mathrm{~cm}$ & $2(6.8 \%)$ & $10(26.3 \%)$ & $<0.001$ \\
\hline
\end{tabular}

In the evaluation of lesions according to TASC classification (TransAtlantic Inter-Society Consensus) Type A, lesions were not significantly different in groups. While Type B lesions were significantly higher in group $1, \mathrm{C}$ and $\mathrm{D}$ lesions were significantly higher in group 2 $(\mathrm{p}<0.01)$ (Table 3).

In group 1,26 of the interventions (5 patients interventions were bilateral) were only balloon angioplasty (89.65\%), and in 3 of the patient's stents (all of them had bilateral lesions) were performed (10.34\%). In group 2, 2 patient's saphenous vein grafts were anastomosed below-knee (5.26\%). In three months follow up, while $78.3 \%$ of patients were asymptomatic in group 1, 90.3\% of patients were asymptomatic in group 2 , and no need additional intervention $(\mathrm{p}<0.01)$ (Table 4). Previous gangrenous regions of extremities were debrided and necrotic fingers were amputated, and amputation rate did not differ between procedure types.

Table 4. Follow up results of patients (regarding operated number of extremity)

\begin{tabular}{|c|c|c|c|c|}
\hline \multicolumn{3}{|c|}{ Number of interventions } & 3 months & 18 months \\
\hline \multirow{3}{*}{\multicolumn{2}{|c|}{ Group $1(n=37)$}} & No symptoms & $29(78.3 \%)$ & $30(81.1 \%)$ \\
\hline & & Intervention & $5(13.5 \%)$ & $3(8.1 \%)$ \\
\hline & & & & \\
\hline \multirow{9}{*}{$\begin{array}{l}\text { Group } 2 \\
(\mathrm{n}=43)\end{array}$} & \multirow{3}{*}{$\begin{array}{l}\text { Saphenous } \\
\text { vein }(n=14)\end{array}$} & No symptoms & $13(92.8 \%)$ & $13(92.8 \%)$ \\
\hline & & Intervention & 0 & 0 \\
\hline & & Surgery & $1(7.1 \%)$ & $1(7.1 \%)$ \\
\hline & \multirow{3}{*}{$\begin{array}{l}\text { PTFE Graft } \\
(\mathrm{n}=29)\end{array}$} & No symptoms & $26(89.6 \%)$ & $26(89.6 \%)$ \\
\hline & & Intervention & $1(3.4 \%)$ & $1(3.4 \%)$ \\
\hline & & Surgery & $2(6.9 \%)$ & $2(6.9 \%)$ \\
\hline & \multirow{3}{*}{$\begin{array}{l}\text { Total } \\
\text { Surgical }\end{array}$} & No symptoms & $39(90.7 \%)$ & $39(90.7 \%)$ \\
\hline & & Intervention & $1(2.3 \%)$ & $1(2.3 \%)$ \\
\hline & & Surgery & $3(6.9 \%)$ & $4(9.3 \%)$ \\
\hline
\end{tabular}

\section{Months Outcomes}

Patients were followed up to 18 months, the rate of graft patency was $90.7 \%$ in Group 2. In group 1, $81.1 \%$ of interventions had no symptoms of ischemia. In Group 2, 4 of the patients required redo bypass (9.3\%), and these patient's extremities had not progressed to amputation. On survival analysis, bypass procedures had better results in the aspect of restenosis compared to angiographic interventions $90.7 \%$ vs $81.1 \%$ at 18 months; $\mathrm{P}<.001)$. The results of saphenous vein bypass patients are better than others. While only one patients need additional surgery in three months, in 18 months follow up also only one patient needed additional surgical procedure (Table 4).

\section{DISCUSSION}

Population studies report a prevalence of intermittent claudication of between $1-7 \%$ in men aged between 50 and 70. The incidence of symptoms is strongly related to age: Claudication affects $2 \%$ of those under InfraInguinal Angioplasty 60 years of age but rises to $5 \%$ in those over 70 (5). The refinement and use of endovascular strategies for the treatment of PAD continued to grow and the use of endovascular procedures for the treatment of PAD increased $4.8 \%$ per year whereas open surgical procedures decreased by $6.6 \%$ per year (6).

The determination of approach in arterial occlusive disease is based on the type and localization of the lesions, patient comorbidities, and also skills of the surgeon (7). Percutaneous transluminal angioplasty looks less invasive and safe and effective method in arterial stenoses but also this procedure contains major complications like hematoma, stenoses, or dissection at the insertion site or through the arterial lumen (8). In our study, we evaluate the 
PTA/S patients and bypass patient's results. In our study, the mean age of patients was 63 in the range of 48 to 78 . In the PTA/S group patient's age was higher than the bypass group ( 65 vs. 61 years, $P>0.01$ ). In both groups, most of the patients were male, but there was no significant difference in the groups in the ratio of male to female. In the aspect of hypertension, diabetes mellitus, renal diseases, smoking there were no significant differences in groups. The risk of contrast-induced nephropathy especially those who had previous borderline kidney functions also determines the choice of treatment for patients with peripheral arterial diseases (9).

In the evaluation of lesions according to TASC classification (TransAtlantic Inter-Society Consensus) Type, A lesions were not significantly different in groups. While Type B lesions were significantly higher in group $1, \mathrm{C}$ and $\mathrm{D}$ lesions were significantly higher in group 2 , (Table 3).

In group 1, 26 of the interventions were only balloon angioplasty (89.65\%), and stents were performed in 3 of the patient's (10.34\%). In group 2, 2 patient's grafts were anastomosed below-knee (5.26\%). Previous gangrenous regions of extremities were debrided and necrotic fingers were amputated, and amputation rate did not differ between procedure types. Patients were followed up to 18 months, the rate of graft patency was $90.7 \%$ in Group 2. In Group 2, 3 of the patients required redo bypass, and these patient's extremities had not progressed to amputation (Table 1).

On survival analysis, bypass procedures had better results in the aspect of restenosis compared to angiographic interventions $90.7 \%$ vs $81.1 \%$ at 18 months (Table 4).

Angioplasty with Drug coated Balloons (DCB) is becoming more preferred over conventional Plain Old Balloon Angioplasty (POBA) in developed countries. A recent metanalysis of randomized controlled trials done to compare the use of DCB and POBA revealed that the use of DCBs has a high ratio in patency and a lower risk of restenosis compared to POBA in patients with the femoropopliteal disease (10). The low incidence of serious complications makes PTA an attractive alternative in the treatment of patients with ischemic foot ulcers. Even in a low-resource setting, PTA is an attractive option for revascularization and wound healing for patients presenting with ischemic ulcers consistent with Rutherford's category five tissue loss (11).

In group 1 hospital stay was significantly lower (1.39 vs 4.38 days $\mathrm{p}<0.01)$. So early mobilization and discharge from hospital affect the hospital-related infections and cost-effectivity positively regarding bypass group. Also, in the aspect of surgical or invasive puncture site infection, the PTA/S group had a lower ratio of $3.44 \%$ vs $13.15 \% \mathrm{p}<0.01$. In these aspects, interventional procedures seem more benefit however in long-term evaluation, freedom from reintervention or redo bypass was significantly higher in the bypass group ( $92 \%$ vs $79 \%$ $\mathrm{p}<0.01)$. Revascularization with PTA/S or bypass allows a very high percentage of limb salvage in diabetic patients with critical limb ischemia (12). In the early period the revascularization, in association with a good medical and surgical approach to foot lesions, results in a very high percentage of limb salvage, with a very low hospital mortality rate. Also, in our study about $50 \%$ of patients were diabetic, and $81 \%$ vs $90 \%$ of patients in group 1 and group 2 consecutively had freedom from reintervention and redo bypass. During the follow-up, the risk of restenosis is higher in diabetic patients as in our study redo cases were diabetic.

Interventional group mortality was $6.88 \%$, but the reason for death was not related directly to the procedure, they had advanced age, and intracerebral hemorrhage was the reason for death, in both group medication for anticoagulant was the same, so the bleeding disorders out of invasive procedure site do not affect the comparison of two methods in the aspect of mortality.

\section{Study Limitations}

The limitation of the study is relatively low patient numbers as in our small cohort sample. Another limitation is the retrospective nature of the study.

\section{CONCLUSION}

The low incidence of serious complications makes PTA an attractive alternative in the treatment of patients with ischemic foot ulcers. Although early and midterm results in aspect of hospital stay and infection, bypass seem to be superior in terms of restenosis/occlusion and reintervention rates. Larger cohort and longer-term results are mandatory to better define this advantage.

\section{ETHICAL DECLARATIONS}

Ethics Committee Approval: The study was carried out with the permission of Non-Interventional Clinical Researches Ethics Committee of İstanbul Medipol University (Date: 03.18.2021, Decision No: 357).

Informed Consent: Because the study was designed retrospectively, no written informed consent form was obtained from patients.

Referee Evaluation Process: Externally peer-reviewed.

Conflict of Interest Statement: The authors have no conflicts of interest to declare.

Financial Disclosure: The authors declared that this study has received no financial support. 
Author Contributions: All of the authors declare that they have all participated in the design, execution, and analysis of the paper, and that they have approved the final version.

\section{REFERENCES}

1. Cheanvechai V, Harthun NL, Graham LM, et al. Incidence of peripheral vascular disease in women: is it different from that in men? J Thorac Cardiovasc Surg 2004; 127: 2: 314-17.

2. Darling JD, McCallum JC, Soden PA, et al. Results for primary bypass versus primary angioplasty/stent for lower extremity chronic limb-threatening ischemia. J Vasc Surg 2017; 66: 466-75.

3. Albers M, Romiti M, Brochado-Neto FC, et al. Meta-analysis of alternate autologous vein bypass grafts to infrapopliteal arteries. J Vasc Surg 2005; 42: 449-55.

4. Papavassiliou VG, Walker SR, Bolia A, et al. Techniques for the endovascular management of complications following lower limb percutaneous transluminal angioplasty. Eur J Vasc Endovasc Surg 2003; 25 : $125-30$

5. Dieter RS, Dieter RA Jr, Dieter RA III (eds). Endovascular Interventions. A Case-Based Approach. 2014th Edition, Doi: 10.1007/978-1-4614-7312-1. Springer, 2014.

6. Jackson MJ, Wolfe JH. Are infra-inguinal angioplasty and surgery comparable? Acta Chir Belg 2001; 101: 6-10.

7. Suraj Wasudeo Nagre, Abhilash J. Long segment femoral endarterectomy with aorto bifemoral bypass grafting for advanced bilateral lower limb peripheral vascular disease in a young male. Vascul Dis Ther 2017; 3: 1-3.

8. Jang BW, Suh KJ, Kim TH, et al. Percutaneous transluminal angioplasty of ilio-femoro-popliteal artery. J Korean Radiol Soc. 1987; 23: 40-7.

9. Habeb M, Agaç MT, Aliyev F. et al. Anadolu Kardiyol Derg 2005; 5: $124-29$.

10. Bradbury AW, Adam DJ, Bell J, et al. Bypass versus angioplasty in severe ischaemia of the Leg [BASIL] trial: an intention-totreat analysis of amputation-free and overall survival in patients randomized to a bypass surgery-first or a balloon angioplasty-first revascularization strategy. J Vasc Surg 2010; 51: 5-17.

11. Cassim MRN, Godahewa S, Paviththiran S, et al. Percutaneous transluminal lower limb angioplasty [PTA] for chronic limb threatening ischemia [CLTI] in a low resource setting 4-year experience. Sri Lanka J Surg 2020; 38: 13-20.

12. Sargın G, Tanriverdi O. A brief overlook at the radial artery catheterization. Med Bull Haseki 2011; 49: 93-5 